\title{
Microbiocenosis characteristics of agrogenically altered acid brown forest soils in humid subtropics of Russia
}

\author{
Elena Rogozhina*, and Lyudmila Malyukova \\ Federal State Budget Scientific Institution «Federal Research Centre the Subtropical Scientific Centre \\ of the Russian Academy of Sciences», 2/28 Jānis Fabriciuss, Sochi, 354002, Russia;
}

\begin{abstract}
Under conditions of perennial cropping of industrial tea crop on acidic brown forest soils of the Black Sea coast of Russia, the following were investigated: number of bacteria, of actinomycetes (mainly the Streptomyces genus) and of micromycetes (saccharomycetes), seasonal dynamics and functional activity of the microbial complex during period of 2008-2019. Stationary experiments were launched in various backgrounds of mineral fertilizer application. The experiment was accompanied by the use of generally accepted recommended techniques for microbiological studies. As follows from the analysis of the data obtained, it was established that the long treatment period of mineral fertilizers at doses from N200P60K50 to N600P180K150 in given soil-climatic conditions under the tea crop contributed to significant decrease in the number of actinomycetes and nitrogen fixing bacteria of the Beijerinckia genus vs. the control variant (without fertilizers). The most significant decrease in the number of micromycetes was revealed immediately after the application of mineral fertilizers at a dose of N600P180K150. After 2 months, the number of this group of soil microorganisms was built back. Under the impact of both medium and high doses of mineral fertilizers, the functional activity decrease of soils $\left(\mathrm{CO}_{2}\right.$ emission and potential nitrogen fixation activity) was noted.
\end{abstract}

\section{Introduction}

The Black Sea coast of Russia has unique soil-climatic conditions for the industrial tea crop, the modern intensive cropping technology of which is associated with the regular application of mineral fertilizers into the soil. Literary sources containing extensive information of researchers on the state monitoring of brown forest soils of tea plantation state the allocated agrogenic changes in physical, physicochemical properties, imbalance of the main biogenic elements, the humus complex transformation towards deterioration of its qualitative composition [1, 2]. Importance assessing of the "soil health" for the resort zone [3-5] and the strategic plan formation for post-agrogenic rehabilitation, the tasks associated with the development of new approach to technologies of turnover regulation of biogenic elements in

${ }^{*}$ Corresponding author: RogojinaEW@yandex.ru 
agroecosystems and the treatment of agrochemicals become urgent. Under these conditions, the role of ecological-agrochemical monitoring of soil state, studies of the trend and intensity of biological processes increases. At the same time, the scientific search segment associated with the allocation and analysis of the composition and structure of the microbiocenosis of agrogenically altered acid brown forest soils of the subtropical zone has not been fully learned. There are no systemic studies of the structural-functional state of microbial complexes, which determines the novelty of this work. The research trend actuality is also confirmed by numerous publications of foreign scientists stating the importance of soil microbial resources for increasing the fertilizer efficiency in the integrated system of soil fertility management of agrocenoses [6-12].

\section{Materials and methods}

Under conditions of the subtropical zone of Russia with the longtime agrogenic impact on the burozems of «Dagomystea» CJSC tea plantation (Uch-Dere settlement) of 1983 plantation year, the stationary experience was launched and the features were studied (number; functional activity, genetic diversity of saprotrophic bacteria) of the soil microbial complex in the period of 2008-2019. Standard soil-ecological approaches were the experiment's technique base: vertically-stepped (profile-genetic distribution); successive (seasonal dynamics). Against background of the application of increasing doses of mineral fertilizers into the soil (N200P60K50; N240P70K90, N600P180K150, 1986 year of the experiment launch) using conventional microbiological methods, the numbers of the main groups of soil microorganisms (bacteria, actinomycetes, and micromycetes) and the total functional activity of soil microbiocenosis (nitrogen fixation and $\mathrm{CO}_{2}$ emission rate) were investigated. Determination of the number of microorganisms was carried out by the widespread method of nutrient plates (Koch method) using dilutions and the soil suspension seeding on elective media. Saprotrophic bacteria were cultured on the meat-and-peptone agar; actinomycetes (Streptomyces genus) - at Gause-1 medium with the penicillin addition (1 mg/l) and nystatin (50 mg/l). Micromycetes - at Chapek's acidated medium. Cellulose-decomposing microorganisms - at Hutchinson's medium, the percentage content of soil foul particles reflecting the development of free-living nitrogen fixers of the Azotobacterecea family, at Ashby's nitrogen-free medium, the total number of bacteria was determined by the photocolorimetric method in P.A. Kozhevin modification using fluorescein diacetate [13-16]. The potential activity determination of nitrogen fixation was carried out by the acetylene reduction method, $\mathrm{CO}_{2}$ emission from the soil - by the absorption method [17] with the titrimetric end.

Study of genetic diversity of saprotrophic soil bacteriocenosis (variants NOP0K0 (control) and N240P70K90) was carried out via RAPD-PCR method in combination with the restriction fragment length polymorphism (RFLP) analysis [18].

\section{Results and discussion}

Study results have established that the total number of active, revivable bacteria of microbiocenosis of agrogenically altered acidic brown forest soils of tea plantations (variants: $\mathrm{N} 0 \mathrm{P} 0 \mathrm{~K} 0$ (control) and N200P60K50) determined by the photocolorimetric method ranged from 750 million to 1.5 billion (Fig. $1 \mathrm{~A}, \mathrm{~B}$ ), and at the nutrient medium (N240P70K90) from 2.6 to 6.1 million CFU/g of abs. dry soil (Fig. 1B), the number of actinomycetes (mainly the Streptomyces genus) and micromycetes (saccharomycetes) from several tens of thousands to 2 million CFU/g of abs. dry soil (Fig. $1 \mathrm{~A}, \mathrm{~B}$, and C), which is generally comparable with the 
data of other researchers of this soil type [19]. The soil profile is characterized by a uniform distribution of bacteria, a significant decrease in the number of actinomycetes (by 1-2 orders of magnitude), and an insignificant variability in the number of micromycetes (within an order of magnitude). In comparison with the control variant (NOP0K0), the system application of mineral fertilizers (N200P60K50 and N240P70K90) contributed to a decrease in the number of actinomycetes at 10-40 $\mathrm{cm}$ depth (by 1 and 2 orders of magnitude, respectively); micromycetes at $0-10 \mathrm{~cm}$ and $40-80 \mathrm{~cm}$ depth by an order of magnitude.

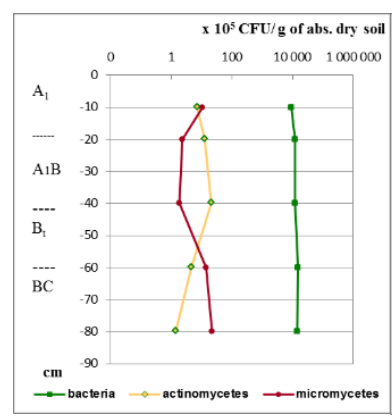

A

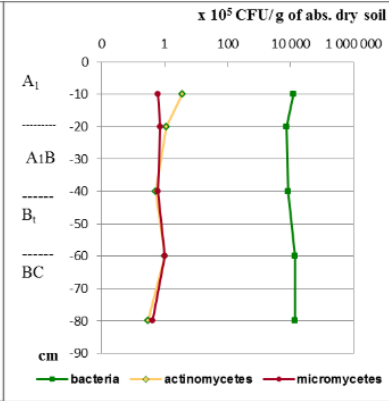

B

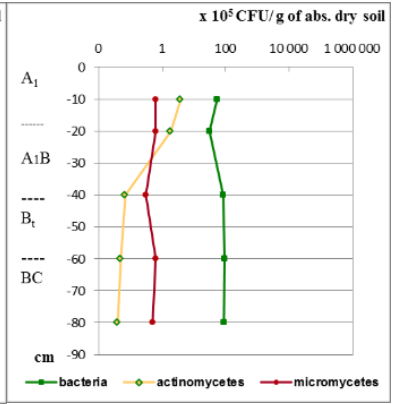

$\mathrm{C}$

Fig. 1 Profile-genetic distribution in soil of bacteria number (A and B - photocolorimetric method), saprotrophic bacteria ( $\mathrm{C}$ - culture technique at solid media), actinomycetes and micromycetes (A, B, C - culture technique at solid media): A - N0P0K0 (2008); B - N200P60K50 (2008); C - N240P70K90 (2014)

The most expressed differences between the variants by a number of indicators were noted for the surface soil layer mostly susceptible to agrogenic impact (Table 1).

Table 1 Impacts of mineral fertilizers on numerical composition of soil microbiocenosis and their functional activity (5-20 cm soil layer, 2008)

\begin{tabular}{|c|c|c|c|c|c|}
\hline \multirow{2}{*}{ Variant } & \multirow{2}{*}{$\mathrm{pH}_{\mathrm{KCl}}$} & \multirow{2}{*}{$\begin{array}{l}\mathrm{CO}_{2} \text { emission } \\
\mathrm{mg} \mathrm{CO}_{2} / \mathrm{kg} \\
\text { average }\end{array}$} & Actinomycetes & Micromycetes & \multirow{2}{*}{$\begin{array}{c}\% \text { of } \\
\text { soil foul } \\
\text { particles }\end{array}$} \\
\hline & & & \multicolumn{2}{|c|}{$\begin{array}{c}\text { Number of microorganisms, } \times 10^{5} \\
\text { CFU/g of abs. dry soil }\end{array}$} & \\
\hline NOP0K0 & 4.2 & $70.3 \pm 13.1$ & $9.2 \pm 4.8$ & $3.8 \pm 0.2$ & 93 \\
\hline N200P60K50 & 3.7 & $63.8 \pm 3.4$ & $3.6 \pm 0.1$ & $3.5 \pm 0.5$ & 78 \\
\hline N600P180K150 & 3.1 & $49.2 \pm 5.2$ & $1.7 \pm 0.2$ & $1.1 \pm 0.2$ & 69 \\
\hline
\end{tabular}

Actinomycetes turned out to be the most sensitive to the impact of mineral fertilizers applied to the soil. The most significant impact of fertilizers at doses of N200P60K50 and N600P180K150 was allocated. Number decrease of the nitrogen fixers of the Beijerinckia genus was also observed. Decrease of soil foul particles for $17-86 \%$ was determined. Reliably revealed decrease of the number of micromycetes (on average by 3 times) was noted under the impact of fertilizers at a dose of N600P180K150.

Against the background of the specific substrate abundance in $10-20 \mathrm{~cm}$ soil layer of tea plantation (cutting material, root litter), the group of cellulose-decomposing bacteria is actively developing. However, against the background of system fertilizer application, the decrease of their number was noted in comparison with the control variant: from 32.8-47.2 CFU/g of abs. dry soil (N0P0K0) to 4.4-22.4 CFU/g of abs. dry soil (N200P60K50). 
While studying the seasonal dynamics of the number of the analyzed groups of microorganisms in agrogenically altered soils, it was established that the variation ranges of the number correlated closely with the thermal, water-air regime of soils, as well as with the mineral fertilizers applied. The number indicators of actinomycetes changed significantly. Against the background of application of increasing doses of mineral fertilizers (N240P70K90), the number of actinomycetes decreased vs. the control variant during the year on average by $\sim 10$ times (Fig. 2). The trend was observed during 3 years of investigations. Significant decrease in the number of micromycetes was revealed only after the application of mineral fertilizers (May, 2015) (30 thousand CFU/g of abs. dry soil in the control variant N0P0K0 and 3 thousand CFU/g of abs. dry soil in variant N240P70K90) and built back within 2 months (June, 2015) (10 thousand and 70 thousand CFU/g of abs. dry soil, respectively). The number of bacteria varied to a greater extent during the year, while no significant differences were allocated between the variants (Fig. 2). It was experimentally determined that the spatial heterogeneity of the number of soil microorganisms of tea plantation (10-20 cm soil layer) under conditions of intensive culture and anthropogenic load on the soil is closely related to the system application of fertilizers; the variability of indicators in the N240P70K90 variant on average was $30 \%$, in the control variant - only $4 \%$.

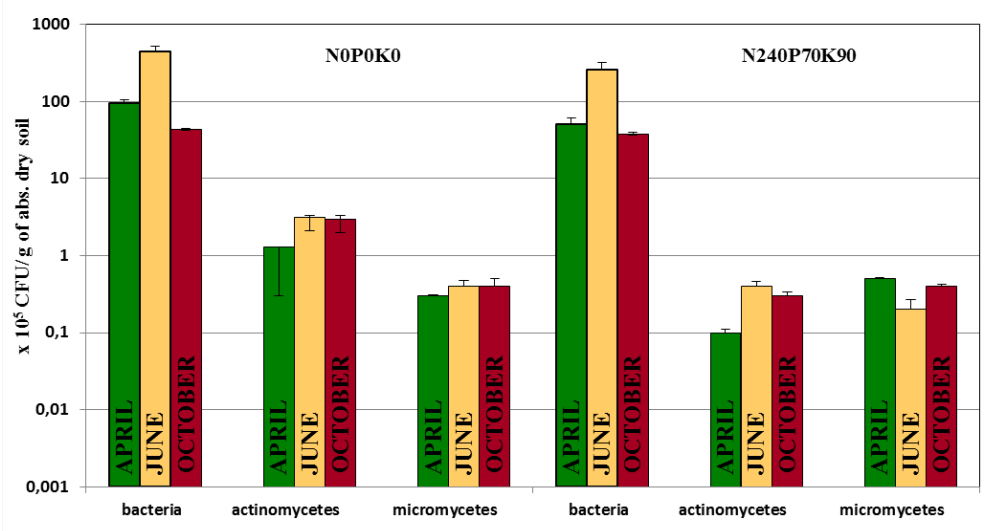

Fig. 2 Number dynamics of main morpho-physiological groups of microbial complex of soils of tea plantation in period from April to October: logarithmic scale (2016)

$\mathrm{HCP}_{0,05}\left(\mathrm{x} 10^{5}\right)$ : bacteria $-4,45$ (April), $\mathrm{Fe}<\mathrm{Ft} *$ (June), 19,91(October); actinomycetes $-0,15$ (April),

0,26 (June), 0,31 (October); micromycetes - 0,21(April), 0,07 (June), 0,11 (October)

* - Fisher's criterion experimental and theoretical.

Investigation of the species (genetic) diversity of soil bacteriocenosis (NOP0K0 and N240P70K90) showed the presence of changes under the impact of fertilizers. By RAPDPCR followed by gel electrophoresis with the denaturating agent gradient of bacterial $r$ DNA in soils of N0P0K0 and N240P70K90 variants (April, June, 2016) was allocated 10 and 9 dominant species of saprotrophic bacteria, respectively. Differences in the species composition of the bacteriocenosis of the soils of the studied variants were confirmed by the absence of genetically identical DNA isolates.

During the entire growing season $(2008,2010)$, there was a decrease of $\mathrm{CO}_{2}$ emission (basal respiration) of soils under the impact of N200P60K50, N600P180K150 fertilizers by $18-62 \%$. Upon that, the variability of these indicators was not high (4-15\%) (2010). Intensity decrease of $\mathrm{CO}_{2}$ emission process correlated with the dose increase of fertilizers (Table 1). During the spring period (2019), under the impact of N240P70K90 fertilizers, the decrease of 
$\mathrm{CO}_{2}$ emissions by $30 \%$ was noted relatively the NOP0K0 control. Potential nitrogen fixation activity in N200P60K50, N600P180K150 variants during the growing season (2008) was decreased by $45-99 \%$ compared to the NOP0K0 control.

\section{Conclusion}

Thus, against the background of prolonged system application of mineral fertilizers in increasing doses under conditions of the acid brown forest soils of a tea plantation, a significant decrease in the number of actinomycetes was revealed (by 10 times or more during the year). The number of micromycetes decreased significantly only in the period after the application of mineral fertilizers (May) and built back within 2 months. Nitrogen fixing bacteria of the Beijerinckia genus were sensitive to both medium and high doses of fertilizers.

The number of saprotrophic bacteria under the impact of fertilizers changed to the least extent; however, differences were discovered in the species composition of the bacteriocenosis in comparison with the control one, which was confirmed by analysis of the genetic polymorphism of the dominant forms.

Under the impact of both medium and high doses of mineral fertilizers, the functional activity decrease of soils $\left(\mathrm{CO}_{2}\right.$ emission and potential nitrogen fixation activity) was noted. Mostly informative indicator was $\mathrm{CO}_{2}$ emission indicator: the process intensity decrease was correlated with the dose increase of fertilizers.

Allocated features of the microbiocenosis of agrogenically altered acid brown forest soils with the system application of mineral fertilizers are the basis for the fertilizer system refinement for industrial tea crop in conjunction with special techniques ensuring the soil biodiversity conservation.

\section{References}

1. N.V. Kozlova, L.S. Malyukova, V.V. Kerimzade, Conceptual model of fertility evolution of acid brown forest soils of tea plantations in humid subtropics of Russia under agrogenic impact: monograph, 76 (Sochi: FRC SSC RAS, 2020)

2. L.S. Malyukova, D.V. Strukova, New Technologies, 3 (49), 164-172, (2019) http://doi.org/10.24411/2072-0920-2019-10315

3. L.S Malyukova Z.V. Pritula, N.V. Kozlova, A.V. Velikiy, E.V. Rogozhina, V.V. Kerimzade, L.S. Samarina, Bangl. J. Bot., 50(1), 179-187 (2021) https://doi.org/10.3329/bjb.v50i1.52686

4. L. V. Zakharikhina, A. V. Burtovoy, Euras. Soil Sci., 53, 820-828 (2020) https://doi.org/10.1134/S1064229320060149

5. J. Habig, C. Swanepoel, Environments, 2, 358-384 https://doi.org/10.3390/environments2030358

6. A. Ahmad, M. Imran, S. Hussain, S. Mahmood, A.H. Houssein, M. Hasnain, J. Sci. Food Agric., 97 (11), 3685-3690 (2017) https://doi.org/10.1002/jsfa.8228

7. F. Battini, M. Gronlund, M. Agnolucci, M. Giovannetti, I. Jakobsen., Sci. Rep., 7, 4686 (2017) https://doi.org/10.1038/s41598-017-04959-0

8. S.T. Berthrong, C.M. Yeager, L. Gallegos-Graves, B. Steven, S. A. Eichorst, R.B. Jackson, et al., Appl. Environ. Microbiol. 80(10), 3103-3112 (2014) http://doi.org/10.1128/AEM.04034-13

9. N.A. Bhat, A. Riar, A. Ramesh, S. Iqbal, M.P. Sharma, S.K., Front. Plant Sci., 8,1523. (2017) http://doi.org/10.3389/fpls.2017.01523 
10. A. Bargaz, K. Lyamlouli, M. Chtouki, Y. Zeroualand, D. Dhiba, Front. Microbiol., 9, 1606 (2018) https://doi.org/10.3389/fmicb.2018.01606

11. A.F. Cruz, T. Ishii, Biol. Open, 1, $52-57$ (2012) http://doi.org/10.1242/bio.2011014

12.E.T. Alori, B.R. Glick, O.O. Babalola, Front. Microbiol., 8, 971 (2017) http://doi.org/10.3389/fmicb.2017.00971

13. G. Doran, A. Zande, Rev. Bras. Ciênc. Solo, 36(2), 349-357 (2012) https://doi.org/10.1590/S0100-06832012000200004

14. H. Ahern, Microbiology: A Laboratory Experience (Open SUNY Textbooks, 2018) https://knightscholar.geneseo.edu/oer-ost/3

15. T.I. Chernov, V.A. Kholodov, B.M. Kogut, A.L. Ivanov, Dokuchaev Soil Bulletin 287 , 100-113 (2017) http://doi.org/10.19047/0136-1694-2017-87-100-113

16. I.O. Kovrigo, E.V. Pershina, E.A. Ivanova, N.S. Matyuk, O.A. Savos'kina, E.L. Chirak, N.A. Provorov, E.E. Andronov, Microbiology, 85(2), 199-210 (2016) https://doi.org/10.1134/S0026261716020107

17. D.A. Sarzhanov, V.I. Vasenev, Yu.L. Sotnikova, A. Tembo, I.I. Vasenev, R. Valentini, Soil Sci., 4, 469-478 (2015) https://doi.org/10.1134/S1064229315040092

18. L. Djokic, M. Savic, T. Narancic, B. Vasiljevic, Archives of Biological Sciences, 62 (3), 559-564 (2011) http://doi.org/10.2298/ABS1003559D

19. G.V. Stoma, N.A. Manucharova, N.A. Belokopytova, Soil Sci., 6, 703-715 (2020) https://doi.org/10.1134/S1064229320060125 